\title{
USULAN PERBAIKAN TATA LETAK FASILITAS PRODUKSI YARN PROCESSING DENGAN METODE SYSTEMATIC LAY OUT PLANNING (STUDI KASUS DI PT. AP Tbk.)
}

\author{
TINA HERNAWATI SURYATMAN,${ }^{1)}$, HARTONO, ${ }^{2)}$ RIFQI MAULANA FADIL ${ }^{3)}$ \\ Program Studi Teknik Industri, Fakultas Teknik \\ Universitas Muhammadiyah Tangerang \\ Email: tinahernawati76@gmail.com, ${ }^{1)}$ hartono269@gmail.com, ${ }^{2)}$ rifqifadil62@gmail.com ${ }^{3)}$
}

\begin{abstract}
PT. AP Tbk. A company engaged in the integrated textile industry, one of the companies that produce various types of high-quality production in yarn manufacturing. Problems that occur at PT. AP Tbk. Superior in yarn processing facilities. In the layout production facility has not been used optimally, location settings are not optimal. found a step back that caused the distance to be far away. For that, it is necessary to restructure the layout of these machines so that the total distance of material handling is faster. Based on the results of research and data processing using a systematic Layout Lay out method, the layout is more efficient when compared to the layout before repair. With the SLP method, two alternative layout locations are produced which can minimize the distance of the material flow and the cost of material handling. Layout 1 can save a distance of 45 meters by issuing material handling costs of 3881.52 rupiah from the initial layout, while layout 2 can save a distance of 57 meters by looking for material handling costs of 4744.08 rupiah from the initial layout. Thus, layout 2 is more recommended so that activities and production results are more optimal and handling of cost material becomes smaller.
\end{abstract}

Keywords: Layout, material handling, material handling costs, work efficiency, Systematic Layout Planning.

\section{PENDAHULUAN}

Dalam dunia industri terutama industri manufaktur, tata letak menjadi faktor utama yang harus diperhatikan, karena suatu perusahaan yang tidak memperhatikan bagaimana penataan dan penempatan ruang serta mesin yang baik, maka itu akan berpengaruh pada seluruh proses yang ada di perusahaan itu nantinya.

PT. AP Tbk. adalah satu perusahaan yang bergerak dalam Industri tekstil, dan menjadi perusahaan tekstil terkemuka yang memproduksi berbagai macam jenis tekstil high quality. Sejak awal berdiri hingga sekarang PT. AP Tbk. sudah berhasil mengirim barang tepat waktu kepada konsumen-konsumennya khususnya untuk produk benang. Mesin-mesin yang digunakan untuk proses pencelupan benang cukup banyak dan bervariasi, tetapi penempatan mesin-mesin tersebut tidak ber- aturan sehingga menjadi hambatan dalam proses produksi. Hal ini berdampak pada jarak total material handling menjadi sangat panjang dan membuat waktu penyelesaian produk jauh lebih lama, untuk itu perlu ditata ulang kembali penempatan mesin-mesin tersebut agar jarak total material handling lebih singkat sehingga dapat meningkatkan efisiensi dalam penyelesaian produk. Perencanaan tata letak sangat memegang peranan penting dalam membuat penjadwalan produksi terutama dalam pengaturan operasi atau penugasan kerja yang harus dilakukan dan tercapailah efisiensi waktu yang makin meningkat.

Penelitian ini dilakukan dengan tujuan:

1. Menghitung jarak material handling pada layout awal untuk proses pencelupan benang pada fasilitas produksi yarn processing; 
2. Menghitung total ongkos material handling pada layout awal untuk proses pencelupan benang pada fasilitas produksi yarn processing; dan

3. Mengetahui perancangan tata letak fasilitas baru pada lantai produksi Yarn Processing sehingga dapat mengurangi jarak total material handling dan ongkos yang diperlukan bisa lebih efektif dan efisien.

\section{METODOLOGI PENELITIAN}

\section{Teknik Pengumpulan Data}

Untuk mendapatkan semua data primer maupun data sekunder, data diambil menggunakan teknik-teknik sebagai berikut:

1. Wawancara

2. Observasi

3. Angket (Kuisioner)

4. Studi dokumen

\section{Teknik Analisis}

Setelah data-data yang diperlukan terkumpul, lalu data diolah dengan metode systematic layout planning.

1. Mengumpulkan data-data yang dibutuhkan untuk membuat relayout fasilitas produksi Yarn processing PT. AP Tbk, seperti data luas bangunan, jarak antar stasiun kerja dan waktu produksi perhari;

2. Membuat data aliran material dari setiap stasiun kerja dari material masuk sampai produk jadi;

3. Membuat grafik hubungan aktivitas (activity relationship chart) untuk menentukan deraja hubungan antar stasiun kerja;

4. Membuat diagram hubungan aktivitas (activity relationship diagram) untuk mengkombinasikan antara derajat hubungan aktivitas dengan aliran material;

5. Menghitung luas area yang tersedia pada setiap stasiun kerja sesuai dengan luas bangunan pabrik yang tersedia;

6. Mengevaluasi kebutuhan luas area untuk pengaturan segala fasilitas stasiun kerja yang dibutuhkan;

7. Menghitung frekuensi aliran material proses produksi;

8. Menghitung jarak antar stasiun kerja layout awal dengan metode rectilinear;

9. Menghitung ongkos material handling pada layout awal;

10. Memodifikasi layout bersadarkan pertimbangan praktis. Pertimbangan-pertim- bangan itu sendiri berkaitan dengan bentuk bangunan, letak kolom penyangga, dan lain-lain yang merupakan dasar pertimbangan untuk memperbaiki alternatif desain layout yang diusulkan

11. Menghitung jarak antar stasiun kerja layout alternatif dengan metode rectilinear

12. Menghitung ongkos material handling layout alternative

Perhitungan Ongkos material handling $(\mathrm{OMH})$ per meter gerakan. Dalam melakukan perhitungan kegiatan material handling dilantai produksi dilakukan dengan mengunakan formula berikut:

1. Ongkos material handling dengan alat

$\frac{\text { biaya pembelian }}{\text { Umur ekonomis } \mathrm{x} \text { waktu dalam I tahun } \mathrm{x} \text { waktu dalam I minggu } \mathrm{x} \text { jam kerja hari } \mathrm{x} 60 \text { menit } \mathrm{x} 60 \text { detik }}$

2. Ongkos Manusia

Upah per jam $=\frac{\text { UMK per bulan }}{\text { Waktu bekerja per bulan }}$

Upah Per Detik $=\frac{\text { UMK per jam }}{60 \text { menit } \times 60 \text { detik }}$

3. Perhitungan per meter handjack \& manusia Kecepatan rata rata asumsi 3 detik / meter

Biaya per meter $=$ waktu $\mathrm{x}$ (handjack + manusia)

13. Mengevaluasi alternatif layout untuk fasilitas produksi yarn processing; dan

14. Penentuan alternatif layout sesuai dengan perbandingan yang telah dilakukan.

\section{ANALISA DAN PEMBAHASAN}

1. Layout Awal

Layout awal merupakan kondisi actual yang ada di departemen Yarn processing saat ini, dengan data layout awal ini juga menjadi patokan dalam perancangan layout alternatif. Berikut adalah gambar layout awal departemen Yarn processing:

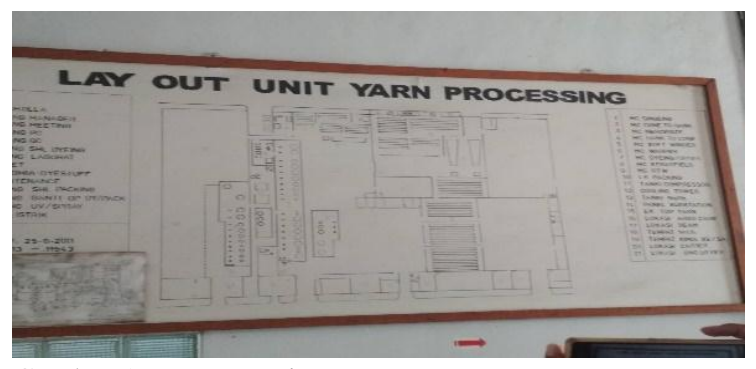

Gambar 1. Layout Unit Yarn processing 


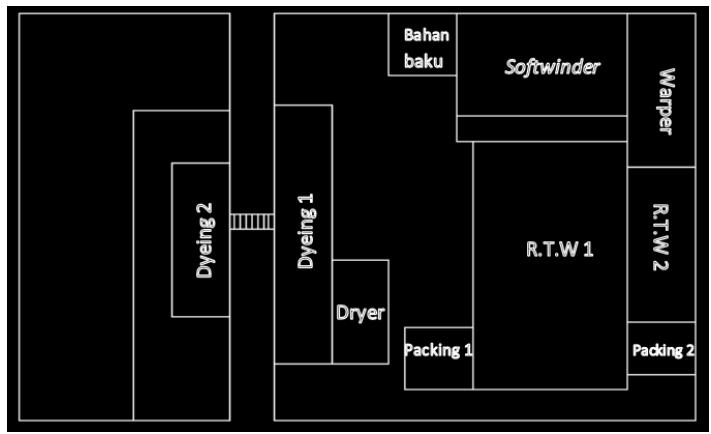

Gambar 2. Layout Awal Departemen Yarn processing

Prinsip kerja proses produksi Yarn processing. Pertama-tama berasal dari bahan baku yaitu benang greige, lalu di proses melalui mesin softwinder dan mesin warper lalu diteruskan hingga proses terakhir yaitu proses R.T.W. Hasil dari proses R.T.W yaitu berupa benang yang sudah berwarna yang selanjutnya di packing dan dipasarkan.

Proses produksi yang ada pada Yarn processing yaitu:

\section{Softwinder}

Menggulung benang dari bentuk paper cones ke bentuk stainless tube untuk proses dyeing.

2. Warper

Pemindahan gulungan dari gulungan cones menjadi gulungan boom sesuai dengan panjang yang ditentukan

3. Dyeing

Mencelup benang dalam bentuk cheese atau beam mulai dari proses scouring, bleaching sampai pewarnaan.

4. Dryer

Mengeringkan benang dengan menggunakan uap panas yang dialirkan dengan bantuan blower.

\section{R.T.W}

Menggulung benang dari bentuk cone tube ke bentuk cone paper dan boom.

6. Packing

Pengepakan benang yang disesuaikan menurut lot, warna dan lain-lain.

\section{Aliran Material}

Pola aliran material yang ada pada Yarn processing adalah aliran material berbentuk $\mathrm{U}$, dimana aliran masuk dan aliran keluar produk berada pada lokasi yang relatif sama. Dan pola aliran material tersebut terdapat beberapa aliran yang cukup memiliki jarak cukup jauh, yaitu salah satunya pada area dyeing 2 yang berlokasi jauh diluar proses warping, sehingga diperlukan waktu cukup lama untuk menuju area tersebut.

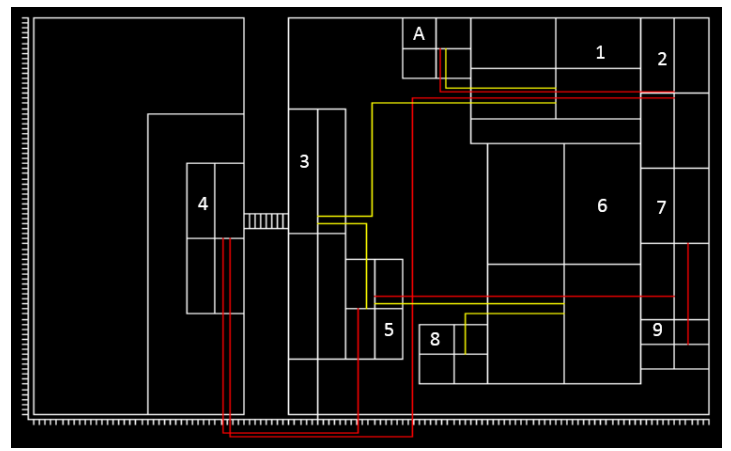

Gambar 3. Pola Aliran Material Produksi Yarn processing

Keterangan:

Garis kuning: produk 1

Garis merah: produk 2

\section{Activity relationship chart}

Activity relationship chart (ARC) ini menggambarkan hubungan kedekatan antar setiap ruangan yang ada pada departemen Yarn processing. Dalam pembuatan diagram ARC ini secara khusus hanya berfokus pada area proses produksi. Hal ini untuk mempermudah dalam pembuatan lokasi perancangan layout terutama pada area produksi yang sangat menunjang. Berdasarkan observasi di lapangan dalam penentuan faktor yang mempengaruhi derajat kedekatan ada 6 faktor utama yang menjadi dasar penentuan derajat kedekatan yaitu:

Tabel 1. Faktor Derajat Kedekatan

\begin{tabular}{|c|l|}
\hline Symbol & \multicolumn{1}{|c|}{ Faktor Kedekatan } \\
\hline 1 & Urutan aliran material \\
\hline 2 & Keamanan dan keselamatan \\
\hline 3 & Hubungan kegiatan produksi \\
\hline 4 & Jarak setiap stasiun kerja \\
\hline 5 & Kualitas hasil \\
\hline 6 & Kebersihan, kerapihan, kenyamanan \\
\hline
\end{tabular}

(sumber: Yudawan, 2011)

\section{Hubungan Aktivitas Area Proses Pro- duksi}

ARC area produksi menggambarkan hubungan kedekatan tiap stasiun kerja secara hanya pada area proses produksi yang berhubungan secara langsung dalam urutan material dan proses yang ada di departemen Yarn processing. Hal ini dapat dilihat pada gambar berikut: 


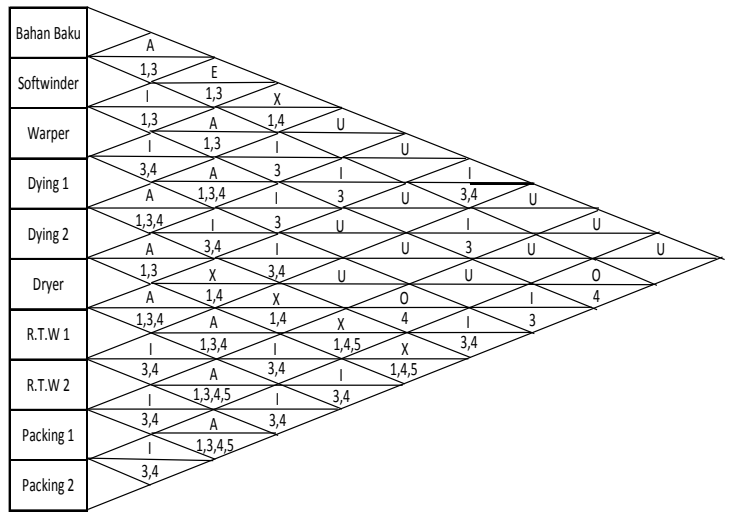

Gambar 4. ARC Area Proses Produksi Yarn processing

Tabel 2. Faktor Kedekatan dan Derajat Kedekatan

\begin{tabular}{|c|c|c|c|}
\hline simbol & faktor kedekatan & derajat kedekatan & deskripsi \\
\hline 1 & urutan aliran material & $\mathrm{A}$ & Mutlak \\
\hline 2 & keamanan dan keselamatan & $\mathrm{E}$ & sangat penting \\
\hline 3 & hubungan kegiatan produksi & $\mathrm{I}$ & penting \\
\hline 4 & jarak setiap departemen & 0 & cukup \\
\hline 5 & kualitas hasil & $U$ & tidak penting \\
\hline 6 & kebersihan, kerapihan, kenvamanan & $\mathrm{X}$ & tidak dikehendaki \\
\hline
\end{tabular}

Tabel 3. Kebutuhan Luas Area Produksi

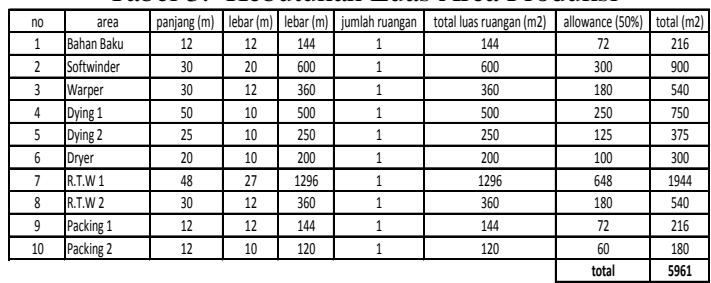

Sumber: data diolah

Tabel 4. Kebutuhan Luas Area Pendukung

\begin{tabular}{|c|c|c|c|c|c|c|c|c|}
\hline no & area & paniang $(m)$ & |lebar $[\mathrm{m}$ & a1 lebar $(m) \mid$ & jumlahrrangan & totall llass andargan (m) & allowance [50\%] & | total[(m2] \\
\hline \multirow[t]{3}{*}{1} & kantor & & & & & & & \\
\hline & ruangac & 10 & 4 & 40 & 1 & 40 & 20 & 60 \\
\hline & ruangmeting & 6 & 4 & 24 & 1 & 24 & 12 & 36 \\
\hline 2 & mustola & 5 & 3 & 15 & 1 & 15 & 7.5 & 22.5 \\
\hline 3 & $1 \mathrm{ab}$ & 10 & 5 & 50 & 1 & 50 & 25 & 75 \\
\hline 4 & ruang mantenance & 20 & 5 & 100 & 1 & 100 & 50 & 150 \\
\hline 5 & 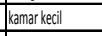 & & & & & & & \\
\hline & pria & 5 & 3 & 15 & 1 & 15 & 7.5 & 22.5 \\
\hline & wwanita & 5 & 3 & 15 & 1 & 15 & 7.5 & 22.5 \\
\hline & & & & & & & total & 388.5 \\
\hline
\end{tabular}

Sumber: data yang diolah

Luas area yang tersedia untuk relayout adalah $9401 \mathrm{~m}^{2}$, sementara kebutuhan luas area adalah $6349.5 \mathrm{~m}^{2}$, masih terdapat $3051,5 \mathrm{~m}^{2}$.

Tabel 5. Frekuensi Material handling

\begin{tabular}{|c|c|c|c|c|c|}
\hline Dari-Ke & $\begin{array}{c}\text { Jumlah } \\
\text { Unithari }\end{array}$ & Berat/Unit (Kg) & $\begin{array}{c}\text { Kapasitas Angkut } \\
(\mathrm{kg})\end{array}$ & $\begin{array}{c}\text { Jumlah Alat Angkut } \\
\text { (orang) }\end{array}$ & Frekuensi \\
\hline $\mathrm{A}-1$ & 3600 & 1 & 600 & 1 & 6 \\
\hline $\mathrm{A}-2$ & 4 & 400 & 400 & 1 & 4 \\
\hline $1-3$ & 3350 & 1 & 600 & 1 & 6 \\
\hline $2-4$ & 4 & 400 & 400 & 1 & 4 \\
\hline $3-5$ & 3350 & 1 & 600 & 1 & 6 \\
\hline $4 \cdot 5$ & 4 & 400 & 400 & 1 & 4 \\
\hline $5 \cdot 6$ & 2620 & 1 & 600 & 1 & 4 \\
\hline $5 \cdot 7$ & 4 & 400 & 400 & 1 & 4 \\
\hline $6-7$ & 2000 & 1 & 600 & 1 & 3 \\
\hline $7 \cdot 9$ & 4 & 400 & 400 & 1 & 4 \\
\hline
\end{tabular}

Sumber: PT. AP Tbk.
Tabel 6. Jarak Antar Stasiun

\begin{tabular}{|c|c|c|c|c|}
\hline \multirow{2}{*}{ Kode } & Area & $\mathrm{X}$ & $\mathrm{Y}$ & Jarak (m) \\
\hline A & Bahan Baku & 72 & 74 & \\
\hline 1 & Softwinder & 93 & 70 & 17 \\
\hline 2 & Warper & 114 & 65 & 33 \\
\hline 3 & Dying 1 & 51 & 37 & 75 \\
\hline 4 & Dying 2 & 33 & 36 & 110 \\
\hline 5 & Dryer & 61 & 22 & 5 \\
\hline 5 & Dryer A & 61 & 22 & 14 \\
\hline 6 & R.T.W 1 & 94,5 & 31 & 42,5 \\
\hline 7 & R.T.W 2 & 114 & 35 & 66 \\
\hline 8 & Packing 1 & 75 & 13 & 37,5 \\
\hline 9 & Packing 2 & 114 & 15 & 20 \\
\hline
\end{tabular}

Sumber: data yang diolah

\section{Analisis Perhitungan Jarak Dan Ongkos Material handling}

Berdasarkan perhitungan yang telah diakukan pada layout awal dan usulan, maka akan disajikan tabel perbandingan antara layout Awal dan alternatif sebagai alternatif yang lebih direkomendasikan untuk digunakan karena mendapatkan jarak yang lebih kecil serta ongkos material handling yang kecil.

Tabel 7. Perhitungan Ongkos Material handling

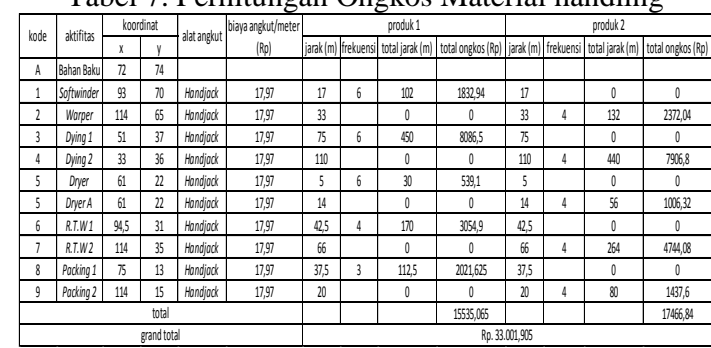

Sumber: data yang diolah

Tabel 8. Perbandingan OMH Layout Awal Dan Aternatif

\begin{tabular}{|c|c|c|c|c|}
\hline Layout Awal & Layout Alternatif 1 & Layout Alternatif 2 & \multirow{2}{*}{ selish (Rp) } & Penghematan \\
\cline { 1 - 3 } $\begin{array}{c}\text { Ongkos Material } \\
\text { Handling (Rp)/hari }\end{array}$ & $\begin{array}{c}\text { Ongkos Material } \\
\text { Handling (Rp)/hari }\end{array}$ & $\begin{array}{c}\text { Ongkos Material } \\
\text { Handling (Rp)/hari }\end{array}$ & & \\
\hline $333.01,91$ & $29.120,39$ & $28.257,83$ & $4.744,08$ & $14,38 \%$ \\
\hline
\end{tabular}

Sumber: data yang diolah

6. Alternatif Layout Final

Tabel 9. Perbandingan Jarak Tempuh Layout Awal dan Alternatif

\begin{tabular}{|c|c|c|c|c|}
\hline Layout Awal & $\begin{array}{l}\text { Layout Alternatif1 } 1 \\
\end{array}$ & Layout Alternatif 2 & & \\
\hline $\begin{array}{l}\text { Total Jarak Material } \\
\text { Handling (m) }\end{array}$ & $\begin{array}{l}\text { Total Jarak Material } \\
\text { Handling }(\mathrm{m})\end{array}$ & $\begin{array}{l}\text { Total Jarak Material } \\
\text { Handling (m) }\end{array}$ & Selish (m) & Penghematan \\
\hline 420 & 375 & 363 & 57 & $\begin{array}{l}3.57 \% \\
\end{array}$ \\
\hline
\end{tabular}

Sumber: data yang diolah

Alternatif yang disarankan untuk dipilih adalah pada alternatif 2, karena diperoleh jarak yang lebih pendek dan ongkos material yang lebih sedikit yang diharapkan dapat membantu peningkatan proses produksi departemen Yarn processing. Berdasarkan keputusan tersebut maka alternatif layout final departemen Yarn processing disajikan dalam gambar 5 berikut: 


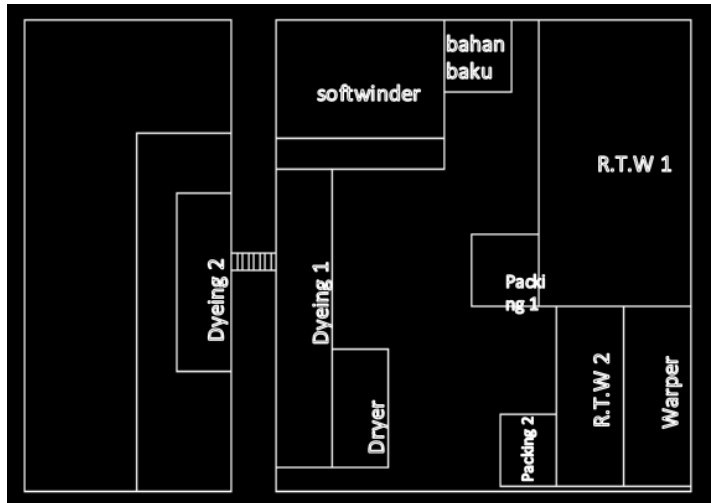

Gambar 5. Layout Final Departemen Yarn processing

\section{KESIMPULAN}

Berdasarkan hasil penelitian, anaisa dan pembahasan, maka didapatkan kesimpulan sebagai berikut:

1. Total jarak material handling layout awal untuk proses pencelupan benang pada fasilitas produksi yarn processing yaitu bahan baku ke softwinder sepanjang 17 meter, bahan baku ke warper sepanjang 33 meter, softwinder ke dyeing 1 sepanjang 75 meter, warper ke dyeing 2 sepanjang 110 meter, dyeing 1 ke dryer sepanjang 5 meter, dyeing 2 ke dryer sepanjang 14 meter, dryer ke R.T.W 1 sepanjang 42,5 meter, dryer ke R.T.W 2 sepanjang 66 meter, R.T.W 1 ke packing 1 sepanjang 37,5 meter, R.T.W 2 ke packing 2 sepanjang 20 meter. Dengan total jarak tempuh keseluruhan sepanjang 420 meter.

2. Total ongkos material handling layout awal untuk proses pencelupan benang pada fasilitas produksi yarn processing yaitu bahan baku ke softwinder sebesar 1.832,94 rupiah, bahan baku ke warper sebesar 2.372,04 rupiah, softwinder ke dyeing 1 sebesar 8.086,5 rupiah, warper ke dyeing 2 sebesar 7.906,8 rupiah, dyeing1 ke dryer sebesar 539,1 rupiah, dyeing 2 ke dryer sebesar 1.006,32 rupiah, dryer ke R.T.W 1 sebesar 3.054,9 rupiah, dryer ke R.T.W 2 sebesar 4.744,08 rupiah, R.T.W 1 ke packing 1 sebesar 2.021,625 rupiah dan R.T.W 2 ke packing 2 sebesar 1.437,6 rupiah. Dengan total biaya ongkos material handling keseluruhan sebesar 33.001,905 rupiah.

3. Berdasarkan pengolahan data menggunakan metode Systematic Layout Planning, didapatkan 2 alternatif. Dari kedua alternatif yang diberikan alternatif yang paling sesuai adalah pada alternatif ke dua. Pertimbangan ini adalah berdasarkan pada perhitungan yang telah dilakukan melalui data dan informasi yang telah didapatkan dan juga melalui perhitungan jarak dan ongkos material handing dimana hasil capaian jarak dan ongkos $m a-$ terial handling yang dipilih adalah yang paling pendek dan sedikit. Sedangkan dari kapasitas kebutuhan luas, kedua alternatif yang dibuat sudah menyesuaikan dengan kebutuhan area pada layout awal sehingga tidak akan terjadi masalah. Berikut ini adalah tabel hasil total jarak tempuh dan total ongkos material handling yang membandingkan layout awal dengan layout alternatif.

Tabel 10. Perbandingan Jarak Tempuh Total

\begin{tabular}{|l|c|c|}
\hline Keterangan & Jarak Tempuh & Satuan \\
\hline Layout awal & 420 & meter \\
\hline Alternatif 1 & 375 & meter \\
\hline Alternatif 2 & 363 & meter \\
\hline
\end{tabular}

Tabel 11. Perbandingan Ongkos Material handling Total

\begin{tabular}{|l|c|c|}
\hline Keterangan & Ongkos Material Handling & Satuan \\
\hline Layout awal & $33.001,91$ & Rupiah \\
\hline Alternatif 1 & $29.120,39$ & Rupiah \\
\hline Alternatif 2 & $28.257,83$ & Rupiah \\
\hline
\end{tabular}

\section{DAFTAR PUSTAKA}

Anwar, Bakhtiar, \& Nanda R. (2015). Usulan Perbaikan Tata Letak Pabrik dengan Menggunakan Systematic Layout Planning (SLP) di CV. Arasco Bireuen. Malikussaleh Industrial Engineering Journal, 4(2), 4-10.

Azwir, H.H, \& Pratomo, W.H. (2017). Implementasi Line Balancing untuk Peningkatan Efisiensi di Line Welding. Jurnal Rekayasa Sistem Industri. 6(1), 57-64.

Bahale, A.P., \& Deshmukh, S.S. (2014). Improving Material Handling Efficiency in a Ginning Machine Manufacturing Company, International Journal of Innovative Research in Science Engineering and Technology. 3(3), 10180-10186. 
Chandra, M. (2011). Perancangan Ulang Tata Letak Fasilitas Lantai Produksi Proses Perakitan Sofa, (Skrispi yang dipublikasikan), Fakultas Sains Dan Teknologi, Universitas Islam Negeri Sultan Syarif Kasim , Riau.

Cundara, N., Sugito, E., \& Sanusi. (2017). Usulan Perbaikan Sistem Material Handling Dengan Menggunakan Systematic Layout Planning (SLP). Jurnal Ilmiah Teknik Industri, 2(1), 91-102.

Dwiharsanti, M., Gumilar, G., \& Siswanto, H. (2016). Perancangan Ulang Tata Letak Fasilitas Laboratorium Pengujian Balai Besar Logam Dan Mesin. Jurnal Metal, 38(2), 56-67.

Faishol, M., Hastuti, S., \& Ulya, M. (2013). Peracangan Ulang Tata Letak Fasilitas Produksi Pabrik Tahu Srikandi Junok Bangkalan. Jurnal Argointek, 7(2), 57-65.

Hossain, M.R., Rasel, M.K., \& Talapatra, S. (2014). Increasing Productivity through Facility Layout Improvement using Systematic Layout Planning Pattern Theory, Global Journal Of Researches In Engineering. 14(7), 71-76.

Maheswari, H. \& Firdauzy, A.D. (2015). Evaluasi Tata Letak Fasilitas Produksi Untuk Meningkatkan Efisiensi Kerja Pada PT. Nusa Multilaksana. Jurnal Ilmiah Manajemen dan Bisnis, 1(3), 5683.

Maryana, \& Meutia, S. (2015). Perbaikan Metode Kerja Pada Bagian Produksi Dengan Menggunakan Man And Machine Chart. Jurnal Teknovasi, 2(2), 15-26

Mieftah, E.M. (2009). Usulan Perbaikan Tata Letak Dan Fasilitas Area Produksi (Skrispi yang dipublikasikan). Fakultas Teknik, Universitas Sebelas Maret, Surakarta

Nugroho, R.O. (2012). Analisis Perancangan Ulang Tata Letak Fasilitas Produksi Pabrik Lama Pada CV. Massitoh Catering Services (Skrispi yang dipublikasikan). Fakultas Ekonomi dan
Managemen, Institut Pertanian Bogor, Bogor

Pratiwi, I., Muslimah, E., \& Aqil, A.W. (2012). Perancangan Tata Letak Fasilitas Di Industri Tahu Menggunakan Blockplan. Jurnal Ilmiah Teknik Industri, 11(2), 102-112

Rengganis, E. (2015). Perbandingan Optimasi Re-Layout Penempatan Fasilitas Produksi Dengan Menggunakan Craft Guna Meminimalkan Biaya Material Handling. Jurnal Angkasa, 7(1), 181-198

Shah, C.R., \& Joshi, A.M. (2013). Increased Productivity In Factory Layout By Using Systematic Layout Planning (SLP), International Journal of Advanced Engineering Technology. 4(4), 61-63.

Siska, M., \& Hendriadi. (2012). Perancangan Ulang Tata Letak Fasilitas Pabrik Tahu Dan Penerapan Metode 5S. Jurnal Teknik Industri. 13(2), 133-141.

Sutari, O., \& Rao S. (2014). Development Of Plant Layout Using Systematic Layout Planning (SLP) To Maximize Production, International Journal of Mechanical And Production Engineering. 2(8), 63-66.

Winarno, H. (2010). Analisis Tata Letak Fasilitas Ruang Fakultas Teknik Universitas Serang Raya Dengan Menggunakan Metode Activity Relationship Chart (ARC). Jurnal Teknik Industri, 2(3), 1-10.

Wiyaratn, W., \& Watanapa. A. (2010). Improvement Plant Layout Using Systematic Layout Planning (SLP) for Increased Productivity, International Journal Of Industrial And Manufacturing Engineering. 4(12), 1382-1386.

Wulansari, A., \& Yohanes, A. (2010). Perencanaan Ulang Tata Letak Fasilitas Produksi Untuk Penanganan Masalah Material Handling Dan Tata Ruang Di PT. Jamu Indonesia Simona. Jurnal Dinamika Teknik, 4(2), 13-23.

Yudawan, A.P. (2011). Penataan Ulang Tata Letak Pabrik Asesoris Mobil Berbahan 
Polimer Pada PT. FLN Dengan Metode Systematic Layout Planing (Skrispi yang dipublikasikan). Fakultas Teknik, Universitas Indonesia, Depok.
Yohanes, A. (2011). Perencanaan Ulang Tata Letak Fasilitas Di Lantai Produksi Produk Teh Hijau Dengan Metode From To Chart Untuk Meminimumkan Material Handling Di PT. Rumpun Sari Mendini. Jurnal Dinamika Teknik, 5(1), 59-71. 